Editor
Richard F. Lewis

Managing Editor
Patricia A. Dolan Lewis

Designer
Paul McCormick

Typography
Hanington Publications

Printing

Alantic Nova Print

Officers of AMTEC

President

Board of Education

Past President

Department of Education

Saskatchewan

Vice Presiden

Tom Rich

Department of Education

Secretary/Treasurer

Guy Leger Separate School Board

Toronto

Director
Bill Hansen

Bill Handsen
Bard of Education

Calgary

Director

ouver Community College

Director

June Landsburg
Simon Fraser University

Membership Coordinator

Sally Landerkin

Deadlines

November 1 February 1 May 1

The Canadian Journal of Educational Com munication is published quarterly by the Association for Media and Technology in $\mathrm{Ca}$ ari, M4Z 373. All artich arecopyighte by AMTEC and may be reproduced for nonprofit use without permission provided credit is given to CJEC.

AMTEC Board Reports
Media, Mental Skills and Learning Tasks: The

Attractive Alternative for
Use in Independent Study Instructional Design Bill Winn

Change

Marvin E. Duncan and
Ronald K. Bass ..........

Color Microfiche: An
Research in the area of educational media staes which have been documented by sev eral scholars (e.g. Levie and Dickie, 1973; Torkelson, 1977). Since it is a major purpose of research in our area to develop theory tha designers, the principles and practice of in structional design have followed a paralle evolution. At present, another major step in this evolution is being taken by researchers. abilities are far more malleable than has hitherto been believed, and that many of the mental skills that were thought to remain immutable over a person's lifespan can be this that certain of the problems tradition attributed to "individual differences" can be overcome. If the past is anything to go by, this development, and others associated with practice of instructional design. The purpose of this article is threefold. First, it will briefly trace the evolution of the thinking in our area about what factors in tion of instructional design principlo because the key to instructional design is an understanding of how these factors can be controlled in a way that is beneficial to learners. Secols a the will be addressed. This will involve a review of research on aptitudes and an examinatio of some recent cognitive theory to do with

The Canadian Journal for Educational Communication (CJEC) accepts papers dealand learning. computer assisted instruction, evaluation, instructional design, simulation, gaming, and other aspects of the use of technology in the learning process.

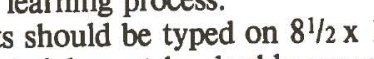
aper. Al authors, identification of each author (postion and institutional or other affiliation (or pared according to the style suggested in the Publications Manual of the American Psy-

Two typed copies of submitted. Visual and graphic materi Winn

\section{welcomed, how}

Manuscripts will be acknowledged as

Submission

Mail manuscripts to:

Atlantic Institute of Education

Halifax, Nova Scotia B3

Deadlines

November

February 1
Bill Winn is an associate professor in the culty of Education at the University of factors is a powerful determinan on nitive psychology is begining tor cognizance of a wide variety

only facto that influenced learning which was worth consideration by instructional designers was to learners. In our area, this pretty much meant the media that were selected or
created to deliver the message. This rather limited view arose from the equally confined outlook of researchers. The onset of the media age in the early fifties was stamped
with an optimism based on the belief that the "new media" were superior to "raditional charged with the responsibility of confirming this supposition. The research paradigm that this charge gave rise to is usually referred to types were compare to cherom instruction, and to each other. Usually, no differences were found, and for every study that

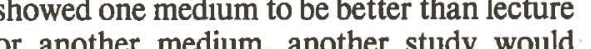
show the opposite. This much has often beet acknowledged, and with hindsight is little cause for surprise. Writers often neglect to

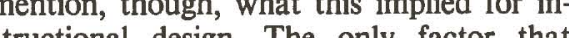
designers had any control over - the medium itself - was shown not to affect learning at all. The reaction of many designers was to go on mediating instruction tive materials The legacy of this practice is with us today. The persistent finding of "no difference" soon led to the realization that what influenced learning was not the medium per se, that were particularly appropriate to various types of learning (Allen, 1967). This led to an analysis of media characterist were varied. For instance, researchers no longer compared film, say, to slides. Rather, they compared realistic pictures to line drawings, motion to still visuals, and color to tion and color are characteristics of visumedia generally. It was at this level that some information useful to instructional designers began to emerge. Many of the principles of design presented by Fleming and Dwyer $(1972,1978)$ reflect the "media char- 
acteristics" approach to research and design. The conclusions that color can be used effec and that line drawings are more effective than realistic pictures in teaching certain They are also medium independent, since color and line drawings can be used in film,
television, slides, posters, textbook illustratelevision, slides,
tions, and so on

Yet sill on 0 ted results sometimes did Yet still expected results sometimes did
not occur. Another factor was brought into consideration to account for this. This was the suspicion that the different media charmight impinge on different learners in different ways (Snow and Salomon, 1968). The research paradigm shifted once again, and now took account or the learners' abilities to learn from different types of mediated as "Aptitude treatment interaction" (ATI), and is dealt with in detail by Cronbach and Snow (1977). The general thesis of the ATI stance, might prove to be more effective than realistic pictures for low ability learners, the reverse might be true for more able ones. This "interaction between learne ability and treatment factors led instruc materials (and instruction in general) for learners of different ability. This often
proved difficult to do, and was not always proved difficult to do, and was not always
cost-effective. A further difficulty arose from the fact that the number of learner-aptitude media-characteristic and subject-matter permutations is enormous. So while some gener-
alizations from the research are possible, most of them are little more than statements

Recently, certain other limitations of the
ATI paradigm have become apparent. This ATI paradigm have become apparent. This
is leading to a reconceptualization of media ch and instructional design.

Beyond Aptitude Treatment Interaction
It is best to illustrate the fundam problem with ATI research by means of an problem with ATI research by means of an
example. In a study of the effect of diagram matic organization of content on learners ability to structure a conceptual domain to
do with biological food chains (Winn, 1980), it was expected that verbal ability would theract with diagrammatic and textua reatments in such a way that the deagram was consistent with Salomon's "supplantation" hypothesis (Salomon, 1979), which states that instructio that supplants mental skils would help low-verbals, because the conten is expressed in a form with which they wil inve less difficulty. The resuls howed oposite to be true. It was found that highhan high-verbals who had seen the tex while there was no difference for lowwas expecte wently been found in two other studies Winn, 1981a; Winn, in press).

A viable explanation of these results is found in Salomon's alternative "activation (n) skills in which learners are adept rather tha supplanting those in which they are weak. In our case, the diagrammat treatne would have actial subjects possessed but which were lacking in the low-verbals. There are two things to consider that arise from this The first is that presenting information low-verbals learn better. There are sever possible reasons for this, the most likely being that, in the studies mentioned above, the diagrammatic treatments tended to be more would take away from low-verbals any advantages granted by the non-verbal presenation. Second is the puzzle created by the fact that verbal ability predicted learning complex question which has been addressed by several researchers.

If the results reported in these studies are to be believed, it seems that the test used to measure verbal ability in fact measured of the construct validity of the verbal test. And it is precisely the construct validity of aptitude tests that has recently come into
question. There is plenty of evidence, a lot of it summarized by Cronbach and Snow (19horndyke and Stasz (1980) on map learn-

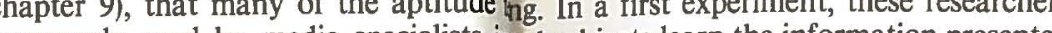
carch or i diagnosis of learner ability an a map of a fictitious country pentil they to making design decisions, do not mexabtained perfect scores. Subjects then what they claim to. Let us return to testlescribed in detail the mental strategies they verbal ability for an example. It has had used in order to leann the information. Frost neborg and Lewis, 1975) that certain teis reach the criterion, the most useful cessing ability, particularly speed. In thed using imagery, mentally partitioning the periments of Hint and his colleagues, venap into sections, and rehearsal. In a second to the speed at which subjects were abine group of subjects, non-helpful skills to a make accurate judgements about the tecond group, and a third group was taugh of statements describing simple vio skills at all. As might be expected, the displays (e.g. " "the cross is above the staroup that had been taught useful skills out claim to, how are researchers and desigudies where relevant mental skills were to proceed? This is a question that hasuccessfully taught to learners have been received attention. Of greatest interest aeported by Weinstein (1978), Weinstein called "aptitude processes", These are 1 The implications of these studies for general aptitudes. Cognitive speed is on:ructional design are far-reaching. Indeed, ample that we have already mentiou may have already realized that the These fundamental processes can be thorndyke and Stasz study was a fine illus processes for what is known abouth be applied to practice (the second ment abilities aptitude tests do measure (Catent). The main implication is that it is no 1976); and by studying test-taking behannger necessary to devote as much time and in order to deduce what cognitive proxifort to identifying strong and weak learner 1978: Snow, 1980). Whichever metholgly. Nor is it necessary to develop differerused, what emerges is a description ots of instructional materials for learners of mental skills that people need to possef erent ability. What is more relevant is to order to perform various learning tentify those mental skills that learners need cositive arce described in terms of apply in incer to learns what they have to, and abilities. Tendered all the more feasible in light of Reducing aptitudes to more fundame growing number of techniques that are constituents has had some quite remarlalable for conducting task analysis in advantages tor ros the ablesign, in ed to employ in order to complete arnes struct validity of aptitude tests. Not $k$ (Resnick, 1976; Greeno, 1976, 1980; among these is the matter of training denn, 1978). Thus, task analysis gains in ers in the mental skills they need in ordportance over learner analysis in the

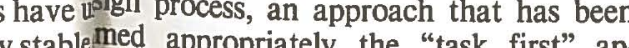

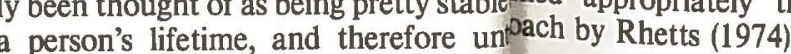

able. However, the processes that un aptitudes are not as stable, and are not cetors That Influence Learning
ant to attempts to train learners in thei We are now in a position to ask the basic
A good example of this appears in a stuetiotion that has been implied since the beginning of this article: What factors conter ing that only the type of medium influences learning. We have seen how certain characteristics of media influence learning directly, or in interaction with the learner aptitudes. skills that underlie these aptitudes influence learning. In addition to these factors (the form of the medium, media characteristics, learner aptitude, and specific mental skills), not yet been mentioned. This is knowledge of the learning task by the learners. The logic of giving knowledge of task frominence in our list of factors that inthe the approsing cannot be attended to, nor can the right mental skills be brought to bear, unless the with the information that is prs to be done has been borne out in two periments (Winn, 1981b), which studied the roles of knowledge of task, instructions to use certain mental skills, and the form the materials in learning patterns and sequences shown either lines or letters one at a time at various locations on a screen, and had either to recreate the figure or pattern that the lines . peared. They were told whether to recall patterns or sequences either before or after the
lines or letters had been presented. In addilines or letters had been presented. In addi-
tion, some subjects received instructions to form images, while others were instructed how to chain one element to the next.
Results showed that subjects who had been cued to the task before presentation outperthe information helped subjects learn. It was also found that sequences were easier to recall than patterns if the elements in them the subjects were shown lines Warious in teractions occurred among the three factors, which suggested that the form of the
materials and instructions to process the inmaterials and instructions to process the in-
formation in a particular way was before they saw the materials. In other words without knowledge of task, learners were no he important for designers to These two experiments are just the beginning of what is hoped to be a fairly length factors (e.g. mental ability) interact and af ect learning. What is important, though, already it appears that the form of th knowledge of task, and maybe even to processing instructions. What this means is tha
instructional designers must not under any constances confine their decisions to co ake. Of more importance is making clear to learners what is expected of them, and giving cessing the information that they are given Instruction should therefore include guid ance on how to learn as well as content to
learned. On the other hand, the designer's ask is made somewhat less difficult by the flexible enough to be trained in the menta skills they need. It is quite likely that, in
many situations, taking the time to train
skills will be more cost-effective than taking ime to develop several alternative forms intruction for learners of different abe co. firmed empirically. However, intuitively

In sum, the great complexity of learnin that research is slowly uncovering reveal than was once believed. This has certain a vantages for the instructional designer, who ather than adapt the instruction to suit the earner. That is not to say that individualizaended. It says, rather, tha here may be circumstances that make the new alternative is tried. The repertoire the designer is increased in this way, to in ional "learner first" approaches. Maybe re "medium first" approach is the best thou his seems unlikely. In any event, our in creasing knowledge of learning is beginnin to attune instruc 
tion more appropriately to tasks and to designers and learners alike.

References
Allen, W.H. Intellectual abilities and instructional media design. $A V$ Commu Allen, W.H. Media stimulus and types of learning. Audiovisuch 12 no. $1,27-31$.

Carroll, J.B. Psychometric tests as cognitive tasks: a new structure of intellect. In $\mathrm{L}$.
Resnick (ed.), The nature of intell. gence. Hillsdale, N.J.: Erlbaum, 1976. Cronbach, L.J., \& Snow, R.E. Aptitudes and instructional

Dansereau, D.F., Collins, K.W., McDonald, B.A., Holley, C.D., Garland, J., Diekhoff, G., \& Evans, S.H. Developmen program. Journal of Educational Psy program. Journal of Edicational
chology, 1979,71 , 64.73 . ized instruction. State College, $\mathrm{Pa}$ : ing Services, 1972

yer, F.M. Strategies for improving visud learning. State College, Pa.. Learning

Levie, W.H. Instructiona message design: Principles from the Edducational Technology Publications,

Greeno, J.G Cognitive objectives of instion: Theory of knowledge for solving problems and answering ques-
tions. In D. Klahr (ed.). Cognition and eeno JG. Some examples of cognitio task analysis with instructional implications. In R.E. Snow, D.A. Federico, \& W.E. Montague. Aptitude, learning and
instruction. Hillsdale, N.J.: Erlbaum,
1980 . Vol. 2 . Hunt, E. The mechanisms of verbal compre-
hension. Psychological Review, 1978,

85, 109-130.
Hunt, E. Frost, N., \& Lunneborg, C. IndiBower (ed.), The psychology of learning and motivation: Advances in research and theory. Vol.

Hunt, E, Lunnebors C \& Lewis, J, What does it mean to be high verbal? Cognitive Psychology, 1975, 7, 194-227.

evie, W.H., \& Dickie, K.E. The analysis nd application of media. In R.M.W. research on teaching. Chicago: Rand McNally, 1973.

Lohman, D. Eye movement differences re flecting aptitude processes. Annual conAssociation, San Francisco, August,

1977.
Lohman, D. Spatial abilities: Individual dif ferences and information processing search Project, Stanford University, September, 1978 .

Resnick, L.B. Task analysis and instructionIn D. Klahr (ed.), Cognition and instruc tion. New York: Wiley, 1976.

Rhetts, J.E. Task, learner and treatment var- of Educational Psychology, 1974, 339.347. Interaction of media, cogn and learning. San Francisco: $\mathrm{J}_{\infty}$

Snow, R.E. Aptitude processes. In R
Snow, P.A. Federico, \& W.E. Ma gue (eds.) Aptitude, learning and struction. Hillsdale, N.J.: Erlba
1980 . now, R.E., \& Salomon, G. Aptitudes ? instructional media. AV Comew, 1968, 16, 341-357. orndyke, P.W., \& Stasz, C. Individu acquisition from maps. Cognitive chology, $1980,12,137-175$.
Torkelson, G.M. AVCR - One qu tury: evolution of theory and res 317-358. ing strategy. In $\mathrm{H}, \mathrm{F}$, O'Neil ing strategy. In H.F. O'Neil
Learning strategies. New York:

einstein, C.E., Underwood, V.L., W
F.L. \& Cubberly, W.E. Cogt learning strategies: verbal and im Spielberger (Eds). Cognit ive learning strategies. New York demic Press, 1979.

inn, W.D. Content structure and a in instructional systems. A Research Association, Toronto, 1 inn, W.D. Simultaneous and succe rocessing of patterns and sequ

inn, W.D. The effect of attribute lighting and spatial organization
identification and classification. Jov I981a, 18, 23-32

Winn, W.D. The effect of block-wor rams on the structuring of scien cepts as a function of general Journal of Research in $1980,17,201-211$. Winn, W.D. The role of diagrammatic ?r of the Learning Resources Ce
sentation in learning sequences,

Marvin E. Duncan is a professor and direcfication and classification as a fun Ronald K. Bass is an associate professor in Research in Science Teaching in an usually brings with it confusion and discomfort. Planned change, however, results in less ing more efficiency and more productivity than unplanned change. In planned change, the initiator of the change idea has a thorough knowledge of the situation to be
changed. The "real" problem and not simply symptoms of the problem are analyzed and clearly identified before attempts to change the problem situation are begun. Proposed ed, and an evaluation of these chimplementbe made in order to determine whether the organization functions more effectively and more efficiently than it functioned prior to of this paper is intended to be a guide to planning instructional change rather than a universal prescription for all change. It is the purpose of this paper to assist the reader in by utilizing a systematic aproanal changes ing a smooth transition from the existing situation to the desired situation

Identifying a Problem

and respond to two perting che agent ask fore attempting to bring about change. Both questions may be answered before a made, depending upon the knowledem the change initiator has of the client system. However, answers to both questions usually

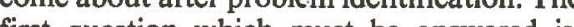
first question which must be answered is, as to whether or not the situation will be changed?" If you have no influence in the sity in, forget $i$ cont chuation will bring and anguish, or possibly dismissal. The sec- ond question is, "Am I concerned to the exnd effor to bing the chut forth the timtion?" If the answer to the latter question yes, proceed. If the answer is no, stop fooling proposed idea.

Ronald G. Havelock $(1970$, p. 12) writ ond develop a viable relationship with the clien system prior to attempts at identifying the oblem situation is not nelon of he entie Rather, establishing a wholesome workin Relationship with those for whom the chan ins necssity. After the proposed change is a lished proceed with identification of the problem. Care should be taken to avoid "finding a solution." This will more than ymptoms rather than to the problem. Usually, as Havelock $(1970$, p. 60$)$ poin out, the obvious is merely a symptom of the problem. Perhaps the most successit ing questions about the situation un by ast mon patterns among symptoms are reco nized. Once the problem has been identified, (he problem. Eliminme Consider the example below: Your office mate comes into the office with wet clothing. The problem appears obvious. It is raining. However, the rain may ing. Your office mate could have gotten we by: 2) walking too closely to a vehicle using 